Cuadernos de Filología Clásica. Estudios Latinos ISSN: 1131-9062

http://dx.doi.org/10.5209/CFCL.62523

\title{
El Epitome de Justino como mina de motivos historiográficos humanísticos. Fenicios, cartagineses y romanos en la ciudad de Gades
}

\author{
Pamina Fernández Camacho ${ }^{1}$
}

Recibido: 19 de marzo de 2018 / Aceptado: 15 de octubre de 2018

Resumen. El libro 44 del Epítome de Justino a las Historias Filípicas de Pompeyo Trogo fue una valiosa fuente de inspiración para los historiadores tardomedievales y humanistas que trataban de construir un pasado para la Península Ibérica, un pasado que no captó la atención de los autores clásicos con anterioridad a la Segunda Guerra Púnica. En este artículo nos centramos en un motivo concreto, de los varios que fueron incorporados a la historiografía hispana a partir de esta obra: la llegada de los cartagineses a la Península como aliados de los gaditanos en un conflicto que estos mantenían con los indígenas. Este motivo alcanzó su máximo desarrollo en la obra de Florián de Ocampo, cronista de Carlos I, que lo utilizó de base para construir una verdadera epopeya plagada de guerras, conquistas y traiciones, culminando con la llegada de los romanos. Su versión inspiró a historiadores posteriores e incluso a cronistas locales, a pesar de las sombras que arrojaba sobre los orígenes de la ciudad gaditana. Nuestro propósito es explorar a fondo el desarrollo de esta construcción histórica, y determinar hasta qué punto el propio Justino puede considerarse el modelo de cada uno de los elementos de la misma.

Palabras clave: Justino; Florián de Ocampo; Agustín de Horozco; Historiografía renacentista española.

\section{[en] Justin's Epitome as a Mine of Historiographical Themes. Phoenicians, Carthaginians and Romans in the city of Gades}

\begin{abstract}
Book 44 of Justin's Epitome of Trogus Pompey's Philippic History was a valuable source of inspiration for late medieval and Renaissance historians who tried to build a past for the Iberian Peninsula; a past which had not caught the attention of ancient authors before the Second Punic War. In this paper we focus on a particular theme, out of several that were taken from this work by Spanish historians: the arrival of the Carthaginians to the Peninsula as allies of the Gaditanians in their war against the natives. This theme was fully developed in the work of Florián de Ocampo, court historian to Charles V, who used it as basis to build a true epic saga full of wars, conquest and betrayal, culminating in the arrival of the Romans. His version inspired later historians and local chroniclers, even though it cast a shadow over the city of Cadiz's origins. Our purpose is to deeply explore the development of this historical construction, and determine to what extent was Justin the model for each of its different elements.
\end{abstract}

Keywords: Justin; Florian de Ocampo; Agustin de Horozco; Spanish Renaissance historiography.

Sumario: 1. Justino y la historiografía española. 2. Florián de Ocampo, Cádiz, y la construcción de la historia de España. 3. Agustín de Horozco: perspectiva local frente a perspectiva nacional. 4. La invasión extranjera: pasado y presente. 5. Bibliografía.

Pamina Fernández Camacho es miembro del grupo de investigación HUM-251 Elio Antonio de Nebrija, bajo la dirección del Prof. J. Ma Maestre Maestre, y pertenece a la Universidad de Cádiz.

Email: pamina.fernandez@uca.es 
Cómo citar: Fernández Camacho, P., «El Epitome de Justino como mina de motivos historiográficos humanísticos. Fenicios, cartagineses y romanos en la ciudad de Gades», Cuad. Filol. Clás. Estud. Lat. 38.2 (2018), 215-227.

\section{Justino y la historiografía española}

Uno de los lugares comunes más frecuentes en la historiografía española del Renacimiento es quejarse de la falta de información sobre la Península Ibérica proporcionada por los historiadores clásicos. Ignorada por su posición periférica y su lejanía de los centros de poder, hasta su irrupción en el conflicto internacional conocido como Segunda Guerra Púnica, esta región del mundo no contaba con una detallada exposición de antigüedades que permitiera a la nueva historiografía nacional sacar pecho ante sus rivales políticos, reclamando una historia más antigua o una monarquía más longeva ${ }^{2}$.

Una de las mayores excepciones a este panorama general de falta de interés por el pasado remoto de la Península la constituía una obra que, a causa de ello, se convirtió en una fuente indispensable para las historias tardo-medievales y renacentistas. Se trata del Epitome de Justino, un resumen de las perdidas Historias Filípicas de Pompeyo Trogo, extensa obra que resumía la historia del mundo conocido por griegos y romanos desde su origen hasta el Principado de Augusto ${ }^{3}$. El libro 44, y último, era una de las escasas fuentes a las que se podía acudir en busca de algunos datos sobre las antigüedades hispanas, que habitualmente eran adornados, transformados y completados con fantasías y construcciones que llenaban los vacíos informativos del texto (Tate 1970, 173-174; Ferrer Albelda 1996, 23, 30-31).

De todos los hechos pretendidamente históricos popularizados por los historiadores que tienen su base en Justino, varios son especialmente importantes: la existencia de una antigua monarquía hispana, con los reyes Gárgoris y Habis como representantes más señalados, la visión positiva de la figura de Gerión como un antiguo rey de Hispania cuyo ganado fue saqueado por Hércules, las distintas interpretaciones evemeristas de una supuesta guerra mitológica contra los Titanes en Tarteso y, lo que interesa a nuestro presente estudio, la invasión cartaginesa y las causas de la misma. El pasaje concreto es el siguiente:

Post regna deinde Hispaniae primi Karthaginienses imperium provinciae occupavere. Nam cum Gaditani a Tyro, unde et Karthaginiensibus origo est, sacra Herculis per quietem iussi in Hispaniam transtulissent urbemque ibi condidissent, invidentibus incrementis novae urbis finitimis Hispaniae populis ac propterea Gaditanos bello lacessentibus auxilium consanguineis Karthaginienses misere. Ibi felici expeditione et Gaditanos ab iniuria vindicaverunt et maiore iniuria partem provinciae imperio suo adiecerunt. (Iust.44.5.1-4 [Seel 1972]).

Después del periodo de los reyes, los cartagineses fueron los primeros en hacerse con el control de la región. Pues, cuando los gaditanos trasladaron los objetos del

Así se manifiesta Ocampo en el Prólogo a su Crónica General, lamentando la falta de "cronistas españoles" en los tiempos antiguos, cuyas obras hubiesen podido competir con la de los autores griegos y romanos, solo preocupados por sus propias ciudades y héroes. (Ocampo 1553, II- IV)

3 Sobre la influencia de Justino en la Edad Media, cf. Castro Sánchez 1995, 35-37. Sobre su redescubrimiento y popularidad a partir del siglo XV, $c f$. n. 5 . 
culto de Hércules desde Tiro (lugar de procedencia también de los cartagineses) hasta Hispania, siguiendo instrucciones recibidas en un sueño, y fundaron allí una ciudad, los nativos de la zona, viendo con malos ojos la prosperidad de la nueva ciudad, les hicieron la guerra. Y por ello los cartagineses enviaron ayuda a los gaditanos, pues sus parientes estaban bajo ataque. Tras una exitosa expedición, no solo libraron a los gaditanos de un tratamiento injusto, sino que, cometiendo ellos mismos una injusticia aún mayor, añadieron una parte de la región a su propio imperio.

Justino atribuye la llegada del primer ejército cartaginés a la Península Ibérica a una guerra entre los fenicios gaditanos y los nativos, que habría impulsado a los primeros a pedir ayuda a sus parientes de Cartago contra los segundos, sirviendo esto de pretexto para la invasión ${ }^{4}$. Este motivo lo encontramos ya en la Estoria de España compilada por el rey Sabio:

Despues de la muerte dErcules acaecio que la cibdat de Caliz, que Espan poblara de las yentes de Tiro que es en Asia, oyeron dezir que Hercules muriera en aquel logar, e ovieron respuesta de sos dioses que si fuesen alla e troxiessen de los sus huessos e daquello que del fincara, que meiorarie siempre la cibdat, ca los gentiles adoravan a Hercules assi cuemo a santo. E pues que esta respuesta ovieron, fueron alla e troxieron daquellas cosas que y fallaron del; e pues que las aduxieron a Caliz, sopieron lo por Espanna, que era toda de gentiles, e fue y tamanna la romería por que se poblo la cibdat muy bien e fizose muy grand. E començaron a apoderarse de la tierra que era enderredor, tanto que sos vecinos avien ende grand envidia, e començaron les a fazer tantas terrerias por que ovieron a aver guerras en uno, de guisa que los de Caliz no lo pudieron soffrir, e ovieron so consejo de cuemo oviessen ayuda qui los defendiesse, e no fallaron logar dond la pudiessen aver tan bien cuemo de Carthago, la de Dido, que es en Affrica. E fazien lo por que los de Carthago fueron allí poblados de Tiro, daquella tierra dond ellos fueron naturales (...) E los de Caliz, teniendo que los daquel logar y ellos eran una cosa por razón de parentesco e que les pesarie el so mal, enviaronles dezir que los ayudasen a librar daquella coyta en que eran con los de Espanna. Los de Carthago, quando lo sopieron, pesoles mucho del tuerto que recibien, e enviaron les grand ayuda por mar (...) mas (...) quando ovieron puesto e sessegado lo de Caliz, començaron a guerrear con los otros de la tierra, assi que ganaron una gran partida daquella provincia (....) (Estoria 1.16 [Menéndez Pidal 1955].)

A pesar de los adornos medievales, como la identificación del motivo de la prosperidad de la ciudad de Hércules con su conversión en lugar de peregrinación religiosa, y su inclusión en una fantasiosa lista de cuatro grandes invasiones, la fuente original del pasaje es claramente identificable con Justino.

El gran erudito Joan Margarit i Pau, arzobispo de Gerona, también recoge el motivo en el libro tercero de su Paralipomenon ${ }^{5}$. El pasaje es una cita casi verbatim del Epitome de Justino:

$4 \quad$ Sobre lecturas modernas de este pasaje, que aún sigue alumbrando distintas interpretaciones $c f$. Ribichini (2000), López Pardo (2010), Álvarez Martí-Aguilar (2014).

5 Contemporáneamente a Margarit i Pau, el Reino de Castilla también se encuentra en el proceso de redescubrir e integrar el material de Trogo/Justino en su historiografía, de la mano de autores como Alfonso de Cartagena y Rodrigo Sánchez de Arévalo, $c f$. Villa Prieto, J. (2010), Alvar Nuño, G. (2017), pp. 95 y ss, 124-125. 
Et quoniam diximus, Iustinus post Trogum Pompeium scripsisse ultimo libro sui Epitomatis, Gaditanos ex Tyriis duxisse originem, qui quum a finitimis Hispaniae impeterentur ab eorum consanguineis Carthaginensibus auxilia petivere, quorum auxilio, ac foelici expeditione, et Gaditanos ab iniuria vindicaverunt, et maiorem partem provinciae suo Imperio adiecerunt; quapropter, a quibus Carthaginienses originem habuerunt, nobis videndum est (...) Iustinus vero post Trog. Pomp. li. XVIII illorum originem prosecutus sic ait (...) (Paralipomenon, 3.1. [Lucero Comas 1994])

Lo que sigue a este pasaje es información detallada, proporcionada asimismo por Justino en el libro 18 de su obra, sobre la fundación de Tiro y la propia Cartago, una conexión a la que volveremos más adelante.

\section{Florián de Ocampo, Cádiz, y la construcción de la historia de España}

Pero será Florián de Ocampo, cronista de Carlos I, quien, en su Crónica General de España, dará una mayor dimensión a la narración contenida en este pasaje, usándola de esqueleto para su épica del pueblo hispano (Ferrer Albelda 1996, 29-33; Fernández Camacho 2016). Después de iniciar la Crónica con un catálogo pormenorizado de los reyes míticos de la Península, tomados de la obra del falsario Annio de Viterbo (Caballero López 2004), Ocampo prosigue su obra acudiendo a Justino. Con ayuda de fuentes secundarias, algunas clásicas y otras espurias, el breve párrafo referente a la llegada de los cartagineses se convierte en una larga historia de traiciones y guerras, donde los fenicios de Cádiz (que, según esta versión, no son los habitantes originales del lugar sino unos extranjeros acogidos por los auténticos gaditanos, los "eritreos", en su ciudad), desempeñan el papel de villanos. A pesar de contar con la amistad y confianza de los gaditanos, se dedican a engañar y atacar a los indígenas; cuando éstos reaccionan, solicitan refuerzos a los cartagineses contra ellos; y, al final, acaban aliándose con los cartagineses para apoderarse de la ciudad, esclavizar a sus primitivos moradores y derrotar a los pueblos vecinos ${ }^{6}$. Todos estos cambios, además de llenar lagunas en la historia antigua del país, servían para crear una imagen continuista del pueblo español, que sufrió invasiones extranjeras sin ser totalmente asimilado por éstas (una idea ya presente en el De rebus Hispanie de Rodrigo Jiménez de Rada tres siglos antes, $c f$. Fernández Valverde 1989, 46-47). También sirven para incluir dentro de este pueblo español a los habitantes originales de Cádiz, una ciudad que, por sí sola, acapara un alto porcentaje de las citas clásicas referidas a la Península Ibérica, pero que era reconocida en la antigüedad como una fundación fenicia ${ }^{7}$.

¿De dónde procede el armazón de esta compleja narración? Podemos reconocer citas, tanto directas como indirectas, de autores griegos, latinos o espurios que uti-

$6 \quad$ Puede encontrarse un útil resumen de todos los pasajes relevantes de la Crónica General en Fernández Camacho (2016, 199-202).

7 No podemos olvidar que los fenicios como pueblo adquirían con frecuencia connotaciones negativas en las fuentes, tanto paganas como cristianas, de la Antigüedad. Como ejemplos significativos, pueden mencionarse las invectivas de los profetas bíblicos contra Tiro (Is.23, Ez.26, 27), el retrato negativo de sus comerciantes en Homero (Ном.Od.14.288 ss y 14.403 ss.), o de los cartagineses como sacrificadores de niños en las Historiae Adversus Paganos de Orosio (5.6). 
lizó Ocampo para adobar el invento, entre los que destacan Plinio, Solino, Avieno, Estrabón, Diodoro Sículo, Virgilio, el "falso Beroso" de Annio de Viterbo, amén de alguna leyenda popular (Ferrer Albelda 1996, 29-31; Fernández Camacho 2016, 204-208.) Sin embargo, el esquema narrativo original, que tiende a atribuirse sobre todo a la creatividad del autor, se encuentra casi por completo en dos pasajes relacionados que epitomizó el propio Justino. Consideramos que Ocampo estableció una conexión, ya antes observada en la obra de Margarit, entre nuestro pasaje del libro 44 y los pasajes del libro 18 que narran la historia de los cartagineses y los fundadores tirios. Los esquemas narrativos que seguían estas historias fueron aprovechados y adaptados a un contexto diferente, dando origen a la nueva narración ocampiana de la ocupación de Cádiz y la Península Ibérica por parte de fenicios y cartagineses.

Veamos, en primer lugar, el caso de la historia de la fundación de Cartago. Según Justino, que aquí ofrece la versión más completa de una popular leyenda, la colonia fue fundada por la princesa tiria Dido, que huyó de su patria después de que su esposo fuera asesinado por el rey Pigmalión (rey que, por cierto, también figura en la historia de Ocampo como el primero en liderar expediciones a la Península Ibérica). Dido, personificación legendaria de la astucia fenicia, se sirvió de estratagemas sucesivas para huir de Pigmalión, para que sus seguidores la acompañaran, para conseguir esposas para éstos, y, finalmente, para conseguir un territorio donde establecerse. La más famosa es sin duda la estratagema de la piel de buey, que citamos con las propias palabras de Justino:

Itaque Elissa delata in Africae sinum incolas loci eius adventu peregrinorum mutuarumque rerum commercio gaudentes in amicitiam sollicitat, dein empto loco, qui corio bovis tegi posset, in quo fessos longa navigatione socios, quoad proficisceretur, reficere posset, corium in tenuissimas partes secari iubet atque ita maius loci spatium, quam petierat, occupat, unde postea ei loco Byrsae nomen fuit. (Iust.18.5 [Seel 1972])

Y Elisa, llegada a un golfo de la costa africana, estableció lazos de amistad con los habitantes del lugar, que se alegraban de la llegada de extranjeros con los que comerciar. Tras adquirir un trozo de tierra, tanto como pudiera ser cubierto por una piel de buey, para que sus acompañantes, agotados por la larga travesía, descansaran hasta que fuera posible retomar el camino, ordenó cortar la piel en trozos finísimos, y de ese modo se adueñó de una extensión de tierra mucho mayor que la que había pedido. De ahí que el lugar más adelante tomara el nombre de Birsa.

Tenemos aquí un ejemplo de "estafa" de los emigrados fenicios a una comunidad nativa que, en principio, se había mostrado receptiva con los recién llegados y dispuesta a acogerlos en su tierra. Dicha estafa tiene como resultado la fundación de Cartago en el espacio abarcado por las tiras de la piel, artificialmente ampliado y en continua expansión. Del mismo modo, los fenicios de Ocampo son bien recibidos en la isla de Cádiz,

cuyos moradores eran gente feroz y no bien aplacada; mas estos de Tyro tuvieron con ellos tales cautelas y los supieron llevar con tan buena manera, que finalmente los recibieron entre sí, permitiéndoles que dentro de su mesma población tomasen la parte que quisiesen donde pudiesen morar (...) Este pedazo del pueblo que les 
fue señalado atajaron los Fenices al principio con palenques y setos vallados (...). (Ocampo 1553, 2.7)

Este espacio limitado cada vez resultará más insuficiente para las ambiciones de los fenicios, que ampliarán su influencia en el territorio a través de similares engaños. En el capítulo 8 de Ocampo, son sus aliados del Puerto de Menesteo (identificado con el actual Puerto de Santa María) los que les permitirán introducirse en las rutas de influencia y comercio de la región. De allí darán el salto a Tarifa, donde se adueñan del "templo de Hércules original", que se encontraba en el Estrecho (un lejano eco del debate sobre su localización en las fuentes antiguas), y, con un pretexto religioso, acaban "robando" las reliquias del dios y trasladándolas a un nuevo templo que construyen, este sí, en Cádiz. Este traslado lo rematan derribando los muros que los separaban de los habitantes originales de la ciudad, y fortificando la ciudadela contra futuros ataques de los indígenas de fuera de ella, «y así todos juntos ellos y los vecinos antiguos de Cáliz comenzaron a cercar la villa de piedra cuadrada, lo mejor obrado que supieron: la cual dicen algunos cronistas castellanos haber sido la primera cerca de lugar en todas aquellas comarcas (...).» (2.9) Obra previsora sin duda, pues a partir del capítulo 11 comienzan las acciones abiertamente imperialistas de los fenicios en el territorio circundante, y en el capítulo 27 estalla la guerra.

En la historia de Cartago de Justino, el primer engaño, aunque no acaba de golpe con la cordialidad de las relaciones con los indígenas, sí constituye una premonición de lo que sucederá luego. Las hostilidades comienzan cuando el rey Yarbas pide la mano de la reina de los cartagineses, un contrato matrimonial que uniría los dos pueblos, bajo amenaza de guerra. (Iust.18.6) Los consejeros de la reina, como buenos fenicios, tratan de engañar a Dido para que acepte el compromiso, pero ella es "mejor fenicia" que ellos y los engaña a su vez, suicidándose y quemando su cuerpo en una pira. La narración fundacional se interrumpe aquí, pero dos detalles aluden a la futura progresión del imperialismo cartaginés: la cabeza de buey que aparece en los cimientos de la futura ciudad es descartada en favor de una cabeza de caballo, bellicosum potentemque populum futurum significans (18.5.15-16, cf. Ribichini 1988, 568-569), y el sacrificio de la reina la transforma en una diosa quamdiu Karthago invicta fuit. (18.6.8) La amistad inicial con los indígenas, que les permite establecerse, es traicionada mediante la apropiación indebida del territorio y luego, por segunda vez, por el rechazo de cualquier posibilidad de alianza entre los dos pueblos: los colonos fenicios solo buscan su propio provecho. Del mismo modo, en Ocampo los fenicios se instalan gracias al buen recibimiento de los eritreos o gaditanos originales, que se consideran sus parientes, pero sobrepasan enseguida los límites del territorio que se les otorga para iniciar acciones en tierra firme cuyo propósito es adquirir riquezas e influencia. La fachada de amistad y armonía empieza, en ambos casos, a resquebrajarse cuando los colonos consiguen edificar su propia ciudad amurallada, su lugar seguro frente a los enemigos potenciales que los rodean. La principal diferencia que presenta la narración de Ocampo es la inclusión de una alianza entre los fenicios y los eritreos gaditanos, que permite que ambos se fusionen por un tiempo en una sola potencia, opuesta a los indígenas de tierra firme. Sin embargo, esta alianza no durará para siempre: es necesario para la narración ocampiana que eritreos y fenicios no lleguen a ser el mismo pueblo.

Esta convivencia de dos pueblos en la misma ciudad nos conduce al segundo pasaje del libro 18 de Justino que sirvió, aún en mayor medida que el anterior, de 
inspiración a Florián de Ocampo para su ampliación de la historia de los fenicios de Cádiz. Se trata de la historia del pueblo tirio, narrada justo antes de la de Cartago y como preludio necesario de esta. Al contrario de lo que observábamos en la narración anterior, en esta narración el enfrentamiento se produce de forma interna, entre dos sectores que habitan la misma ciudad: los tirios libres y sus esclavos.

[Tyrii] a servis suis multitudine abundantibus indigna supplicia perpessi sunt, qui conspiratione facta omnem liberum populum cum dominis interficiunt atque ita potiti urbe lares dominorum occupant, rem publicam invadunt, coniuges ducunt et, quod ipsi non erant, liberos procreant. Unus ex tot milibus servorum fuit, qui miti ingenio senis domini parvulique filii eius fortuna moveretur dominosque non truci feritate, sed pia misericordiae humanitate respiceret. Itaque cum velut occisos alienasset servisque de statu rei publicae deliberantibus placuisset regem ex corpore suo creari eumque potissimum quasi acceptissimum diis, qui solem orientem primus vidisset, rem ad Stratonem (hoc enim ei nomen erat) dominum occulte latentem detulit. Ab eo formatus, cum medio noctis omnes in unum campum processissent, ceteris in orientem spectantibus, solus occidentis regionem intuebatur. Id primum aliis videri furor, in occidente solis ortum quaerere. Ubi vero dies adventare coepit editissimisque culminibus urbis oriens splendere, spectantibus aliis, ut ipsum solem aspicerent, hic primus omnibus fulgorem solis in summo fastigio civitatis ostendit. (...) Tunc intellectum est, quantum ingenua servilibus ingenia praestarent, malitiaque servos, non sapientia vincere. Igitur venia seni filioque data est, et velut numine quodam reservatos arbitrantes regem Stratonem creaverunt. Post cuius mortem regnum ad filium ac deinde ad nepotes transiit. (Iust.18.3.2-15 [Seel 1972])

[los tirios] sufrieron un tratamiento indigno por parte de sus esclavos, cuyo número era inmenso. Estos, urdiendo una conjura, mataron a sus amos y a toda la población libre, $\mathrm{y}$, apoderándose de la ciudad, ocuparon los hogares de sus dueños, accedieron al poder, tomaron esposas, $\mathrm{y}$, siendo ellos esclavos, engendraron hijos libres. Uno de entre todos ellos, compadecido de su anciano amo, que había sido bueno con él, y del destino del hijo pequeño de este, no los trató con salvaje ferocidad, sino con piadosa misericordia y humanidad. Los ocultó fingiendo que los había matado, y cuando los esclavos, tras haber deliberado sobre su sistema político, decidieron nombrar rey a uno de ellos, considerando como el elegido por la voluntad de los dioses a aquel que primero viera la luz del sol naciente, consultó el tema con su amo Estratón (pues este era su nombre) en su escondite. Instruido por este, cuando todos se reunieron en un campo de madrugada, fue el único en mirar hacia el ocaso, mientras todos los demás se volvían hacia el este. Al principio pensaron que estaba loco por esperar que el sol saliera por el oeste, pero cuando el día ya iba llegando, y el astro rey empezó a reflejarse en las torres de la ciudad, él fue el primero en mostrar a los demás, que aguardaban para ver salir el sol, el primero de sus rayos brillando en la más alta de todas ellas. (...) Entonces se vio hasta qué punto aventajaba el ingenio de un hombre libre al de un esclavo, y que éstos podían ganarles en maldad, pero no en sabiduría.

Los tirios originales, los que participaron en la fundación de Cádiz y de Cartago, fueron, según esta leyenda, asesinados por sus esclavos, que los suplantaron y se apoderaron del gobierno de la ciudad. Tan solo la familia de uno de estos tirios libres, 
Estratón, fue salvada, y se le permitió ostentar la dignidad real como resultado de un cúmulo de circunstancias novelescas que recuerdan a la biografía de Darío I (Yardley 1994). Es improbable que nos hallemos ante una auténtica leyenda tiria, debido a las implicaciones injuriosas de la misma, y a la (sospechosamente bien trabada) conexión que se establece en la parte final con un suceso de gran impacto en la política internacional: la conquista de Tiro por parte de Alejandro.

Itaque Alexander Magnus, cum interiecto tempore in Oriente bellum gereret, velut ultor publicae securitatis, expugnata eorum urbe omnes, qui proelio superfuerant, ob memoriam veteris caedis crucibus adfixit; genus tantum Stratonis inviolatum servauit regnumque stirpi eius restituit, ingenuis et innoxiis incolis insulae adtributis, ut exstirpato servili germine genus urbis ex integro conderetur. (IusT.18.3.1617 [Seel 1972])

Y Alejandro Magno, en el transcurso de su campaña oriental, después de tomar la ciudad, hizo crucificar a todos los que sobrevivieron el asedio, como vengador de la seguridad pública y en recuerdo de la antigua masacre. Solo perdonó a la familia de Estratón, y devolvió el trono a sus descendientes, colonizando la isla con nuevos habitantes libres de nacimiento e inocentes de toda culpa, para que, extinguiéndose así la raza servil, pudiera la ciudad repoblarse de nuevo.

En este relato se inspira la otra parte de la historia de las relaciones entre fenicios e indígenas: las relaciones de los fenicios invasores, no con los pueblos de tierra firme que les hacen frente, sino con los eritreos o gaditanos originales, una vez que la alianza inicial entre ellos llega a deteriorarse. En efecto, a partir del capítulo 30 del libro segundo, cuando los fenicios gaditanos piden ayuda a los cartagineses contra sus enemigos, los eritreos van a ir progresivamente desmarcándose de las maniobras de sus protegidos. El punto culminante de esta desafección lo encontramos en los capítulos 34-35, cuando los cartagineses ahondan arteramente en la división para apoderarse ellos mismos de la ciudad. Los eritreos toman armas contra los que hasta entonces habían acogido en el seno de su comunidad, y contra los cartagineses que los apoyan, y se hacen fuertes en la ciudadela que construyeron juntos. Pero ya es demasiado tarde: son conquistados y reducidos por la fuerza a una posición subalterna en la ciudad que ellos mismos fundaron. A partir de entonces, los eritreos, «habiendo perdido su libertad y sin esperanza de recuperarla», pasan a dedicarse exclusivamente a la navegación y a los negocios (2.39). Y sin embargo, al igual que los "tirios libres", no son eliminados del todo, y ello permite al historiador mantener la continuidad con los orígenes ilustres de la isla-ciudad, así como atribuir a este pueblo oprimido las hazañas por las que los gaditanos eran celebrados en los textos clásicos (la exploración de los mares y la pesca y exportación del atún, $c f .3 .3$ y 3.26). El nuevo elemento dominante, sin embargo (la alianza entre los cartagineses y los fenicios gaditanos, que habían sido su avanzadilla) queda como interlocutor político principal, y como protagonista de las guerras contra todos aquellos pueblos que se opusieron a la hegemonía cartaginesa en la Península Ibérica (Fernández Camacho 2016, 207-208). Esta historia es muy similar a la leyenda recogida por Justino, cuyo propósito ideológico fue probablemente muy similar también: hacer compatible la antigua grandeza de la ciudad de Tiro con su carácter negativo de antagonista de Alejandro, y justificar a la vez la conquista (y posterior masacre) por parte de este como 
un restablecimiento de la Tiro original. El giro final de la historia de Tiro, sin embargo, queda sin equivalente en la Crónica General. No sabemos si los eritreos (que recobran una especie de libertad subordinada al dominio de Cartago, $c f .3 .13$, sin que les sean devueltos ni el templo de Hércules ni sus principales fortalezas) resurgirían de sus cenizas para restablecer la ciudad original, limpia ya del elemento usurpador, puesto que Ocampo jamás llegó a terminar su proyecto. En los cinco libros que escribió antes de su muerte no alcanzó siquiera el período en que la Península Ibérica se convierte en uno de los teatros principales de la segunda guerra púnica.

El continuador de la obra de Ocampo, Ambrosio de Morales, menos dado a las fantasías novelescas, seguirá punto por punto la narración de Tito Livio al respecto (Morales, 1574). Es obvio que, para el historiador de Padua, los gaditanos primitivos no podían ser otra cosa que fenicios, que renunciaron a su alianza con los cartagineses para establecer un foedus nuevo con los romanos ${ }^{8}$. De este modo, la historia de la conquista de la ciudad desde dentro y a traición por extranjeros acogidos en su seno queda sin conclusión satisfactoria en la Crónica General, sin restitución de los damnificados ni castigo de los traidores.

\section{Agustín de Horozco: perspectiva local frente a perspectiva nacional}

Un cambio de tercio tan mal ajustado, sin embargo, tenía mayores consecuencias cuando el interés de la obra no era escribir una historia general de España, sino la historia local de Cádiz. Dos obras importantes de este género fueron escritas casi en la misma época, entre la última década del siglo XVI y la primera del XVII: las Grandezas y Antigüedades de la Isla y Ciudad de Cádiz, de Juan Bautista Suárez de Salazar, publicada en 1610, y la Historia de la ciudad de Cádiz de Agustín de Horozco, que fue acabada en 1598 pero que no se publicaría hasta el siglo XIX. Ambas obras tuvieron un destino muy diferente: la de Suárez de Salazar fue publicada inmediatamente y alcanzó un considerable éxito, mientras que la de Horozco permaneció en la oscuridad durante siglos, circunstancia quizá relacionada con su carácter más crítico y menos panegirista ${ }^{9}$. Lo cierto es que, en lo que respecta a la historia de Cádiz en la antigüedad, ambos autores toman caminos muy distintos: Suárez de Salazar rechaza el esquema de Justino, novelado por Ocampo, y decide recopilar ex novo fuentes clásicas sobre la antigüedad de Cádiz, empleándolas como base para elaborar su propio relato elogioso de los ilustres orígenes de la ciudad. Horozco, por el contrario, opta por usar al Justino de Ocampo, y desarrollar esta narración añadiendo elementos de su propia cosecha, cargando las tintas sobre la perfidia de los fenicios, su traición, y la maldad de los aliados cartagineses. El añadido más importante es el final: Horozco no puede resistirse a dar a la historia de la ocupación de Cádiz una conclusión más satisfactoria. Cuando la ciudad cambia de bando durante la segunda guerra púnica,

quedando Cádiz libre y desocupado de los cartagineses, pasó luego su señorío a los romanos (...) con tanto contento de los romanos como de los gaditanos que los

Sobre la existencia y características de este foedus, cf. Liv.28.30-37, 32.2-5, y también Cic.Balb.34, 39.

$9 \quad C f$. los comentarios en la introducción del editor de Horozco sobre el carácter de la obra (Morgado 2017² [2001], 27-31.) 
admitieron en su isla, llamándolos, y poniéndose a su guarda y amparo. Y si algunos cartagineses de los nuevamente advenedizos había en la ciudad limpiáronla de ellos, poniendo en su lugar muchos nobles romanos y españoles (...) (Horozco 2.5 [Morgado 2017]).

Esta "limpieza étnica" no se encuentra en Ocampo ni en Morales, ni en el libro 44 de Justino. Pero, si acudimos al libro 18 de las Historias Filípicas, las semejanzas con la narrativa de la conquista-restauración de Tiro se revelan al fin en su dimensión completa. Recapitulando y comparando ambos episodios, los tirios "verdaderos", los que habían fundado Cádiz y Cartago, fueron masacrados a traición por sus propios esclavos, que se hicieron con el control de la ciudad, del mismo modo que la colonia tiria en Cádiz, con ayuda de sus aliados cartagineses, redujo a los habitantes originales en una guerra interna. Así, los "verdaderos tirios" y los "verdaderos gaditanos" fueron suplantados por una población impostora, no quedando de sus gloriosas ciudades más que el nombre.

Un solo elemento de legitimidad les quedaba a ambas ciudades, que constituía un nexo con el pasado: la familia de Estratón, en el caso de Tiro, y los eritreos sometidos, en el caso de Cádiz. Cuando, siglos más tarde, Alejandro Magno conquistó la ciudad, hizo masacrar a todos los descendientes de los antiguos esclavos, y a los descendientes de Estratón les devolvió la dignidad real. El resto de la población fue sustituida por «colonos nacidos libres, que no tenían ninguna complicidad en aquellos crímenes» (ingenui et innoxii). Con ello, la ciudad quedó restablecida a su grandeza original, clara invención de una fuente propagandística anti-tiria ${ }^{10}$, que justificaría la masacre perpetrada por Alejandro haciéndola pasar por una venganza contra unos criminales, por una parte, y una "limpieza" y "restauración" de la ciudad a una antigua grandeza de la que la revolución interna la había desviado. En Horozco, por primera vez, hallamos el modelo de la historia completa que incluye este final, el cierre del paréntesis de decadencia de la ciudad gaditana mediante una limpieza del elemento usurpador y una restauración del usurpado. Los representantes del pueblo dominado que aún viven dentro de la ciudad son liberados de su sujeción por un invasor justo, los que los habían sometido son eliminados, y el desajuste de la población provocado por dicha eliminación es compensado mediante la introducción de habitantes nuevos que son, de algún modo, "dignos" de ser ciudadanos (colonos libres e inocentes -griegos, se entiende-, en el caso de Tiro, y nobles romanos y españoles en el caso de Cádiz). Horozco ha creado, pues, un final para la historia de Ocampo siguiendo el modelo que, sin duda, él también supo identificar en la obra de su predecesor, y que el foco local de su historia convertía en absolutamente necesario.

\section{La invasión extranjera: pasado y presente}

Si el final era necesario para liberar a Cádiz, sin ambigüedades, de la mala imagen que ofrece en la versión de Ocampo, sin embargo, podríamos preguntarnos si dicha versión era la más apropiada para servir de base a una historia local. El carácter

10 Probablemente Timeo, primera fuente conocida para la leyenda de la fundación de Cartago, que sigue directamente a la de Tiro en el libro 18 de Justino. Cf. Bunnens 1979, 174-183. 
encomiástico y reivindicativo constituye, a fin de cuentas, el rasgo más característico del subgénero historiográfico conocido como corografía (Kagan 1995, 47-59). El ejemplo de Suárez de Salazar, antes mencionado, es ilustrativo al respecto: este autor (cuya obra sí fue publicada en su tiempo) optó por elaborar un relato diferente, eligiendo aquellas fuentes que elogiaban, sin ambages, la antigüedad de Cádiz, su fundación por los marinos ilustres de Tiro, y la leyenda de su patrono Hércules (Suárez de Salazar 1985, 15-23). No había necesidad de introducir un episodio que tenía sentido en una historia de España como nación, pero que arrojaba sombras sobre la historia de Cádiz como ciudad. Sin embargo, como ya apuntaba Morgado en su introducción ${ }^{11}$, la historia de Horozco se caracterizaba precisamente por su dimensión crítica, y por ser incapaz de pasar por alto los defectos que percibía en la sociedad y el gobierno de su ciudad de residencia, aún a la hora de elaborar su historia más remota.

Uno de los principales problemas que veía Horozco en la Cádiz de su tiempo era lo que él consideraba un exceso de población extranjera, propio por otra parte de una ciudad mercantil. Con la ciudad recuperándose aún del asalto de los ingleses en 1596, la seguridad era una preocupación urgente para muchos, y los extranjeros constituían un punto débil visible: gente de lealtad dudosa, que solo se preocupaba de su propio beneficio, y no tenía motivo suficiente para preocuparse por el bien de la comunidad. Se trata de un tema común en los siglos XVI y XVII, como lo demuestran las protestas de las autoridades locales e inspectores reales, que consideraban que la población extranjera constituía un riesgo en tiempos de guerra, una quinta columna en potencia. Como afirma Fernández Reina,

En 1609, temiéndose un ataque holandés, le advierten [al rey] que una de las compañías de vecinos que hacía la guardia nocturna estaba formada exclusivamente de flamencos. En 1643, que las milicias daban poca confianza, porque, de las cuatro compañías de vecinos, tres eran de extranjeros, una de ellas de portugueses, con cuyo país estaba en guerra. Poco después, que dos tercios de la población lo formaban naciones extranjeras poco afectas a la corona española (...) Lo más llamativo es el proyecto de levantar una ciudadela en vez de una muralla perimetral, para asegurarse de una población en gran parte extranjera. Muchos años despúes se reitera esa sugerencia, la ciudadela se considera necesaria a fin de tener con ella en respeto a los vecinos, y oponerse a cualquier sublevación que podría intentarse, y para que la tropa pudiera acudir a la defensa de la plaza sin que los vecinos pudieran estorbarlo ni aun saberlo. (Fernández Reina 2001, 43)

Horozco se suma a este coro de voces admonitorias, considerando que

la ciudad para la contratación y comercio ha recibido y recibe cada día tanta diversidad de gentes de varios pueblos y provincias de España y de fuera de ella, que de ellos... se ha causado mucha confusión, y oscureciendo los originarios y vecinos, yéndose unos a vivir a otras partes en enriqueciendo, y adquiriendo los bienes que no trajeron, y otros entrando con solamente el fin de adquirirlos y granjearlos, blanco y paradero a que todos atienden .... pareciéndome más, que por ser pueblo de esta behetría y variedad de la mezcla de los originarios con los advenedizos, ha 
padecido y padece Cádiz la grande quiebra y disminución de sus privilegios (...) no tratando nadie más que de su particular negocio e interés, y en no atravesando éste, o algún particular fin, todos lo dejan, mayormente si se ha de tener algún trabajo en la negociación, o haber de salir de sus casas y de su regalo. (Horozco, 3.3 [Morgado 2017])

La versión de la historia antigua de Cádiz que Ocampo había ideado a partir del excurso tirio de Justino resultaba, si no la más elogiosa, sí la más adecuada para proyectar sobre el pasado los problemas que el autor detectaba en el presente, mostrando además las consecuencias más extremas que podían derivarse de ellos. Los comerciantes fenicios que vivían en un barrio de Cádiz y llamaban a sus parientes de Cartago, una potencia internacional, para que les ayudaran a tomar la ciudad y el territorio circundante constituían una excelente parábola histórica que escenificaba lo que podía suceder en el peor de los futuros posibles. De este modo culmina el recorrido del "episodio gaditano" del Epitome en la historiografía española: de una utilización más o menos literal del episodio, pasando por una reelaboración imaginativa que hizo posible su conversión en piedra angular de la construcción ocampiana de la historia antigua del pueblo español, hasta su adaptación por parte de la historiografía local, que se esfuerza por mantener un difícil equilibrio entre las glorias de la pequeña patria y las sospechas que el pasaje arroja sobre la identidad de Cádiz y su rol en los orígenes de España, sospechas que hallarán paralelos incómodos en la ciudad mercantil habitada por estos historiadores.

\section{Bibliografía}

Alvar Nuño, G. (2017), Estudio, edición crítica y traducción de la Compendiosa Historia Hispanica de Rodrigo Sánchez de Arévalo, Madrid, UCM, Tesis Doctoral.

Álvarez Martí-Aguilar, M. (2014), «¿Mentira fenicia? El oráculo de Melqart en los relatos de fundación de Tiro y Gadir», en Marco Simón, F., Pina Polo, F., Remesal Rodríguez, J. (eds.), Fraude, mentiras y engaños en el mundo antiguo, Barcelona, Universidad de Barcelona, 13-34.

Antón Solé, P. (1973), «Vida y obra del historiador y almojarife gaditano Agustín de Horozco», Archivo hispalense 56, 75-95.

Bunnens, G. (1979), L'expansion phénicienne en Méditerranée. Bruselas-Roma, Institut Historique Belge de Rome.

Bustos Rodríguez, M. (1991), Historia de Cádiz, vol. 3: Los siglos decisivos. Historia de Cádiz en la Edad Moderna. Madrid, Sílex.

Caballero López, J.A. (2004), «Mito e historia en la "Crónica General de España” de Florián de Ocampo», en Domínguez Matito, F., Lobato López, M. L. (eds.), Memoria de la palabra: Acta del VI congreso de la Asociación Internacional de Siglo de Oro, vol. 1, Burgos/ La Rioja, Iberoamericana, 397-406. (Versión digital: «https://cvc.cervantes.es/literatura/ aiso/pdf/06/aiso_6_1_032.pdf» [15/03/2018])

Castro Sánchez, J. (1995), Justino. Epitome de las Historias filípicas de Pompeyo Trogo, Madrid, Gredos.

Fernández Camacho, P. (2016), «La ciudad bipolar. La construcción de la imagen de Cádiz en la historiografía del siglo XVI a través de las fuentes clásicas," Agora 18, 193-215 (Versión digital: «http://revistas.ua.pt/index.php/agora/article/view/3788» [13/03/2018]). 
Fernández Reina, J. (2001), La ciudad insular. Cádiz, Jiménez-Mena.

Fernández Valverde, J. (1989), Historia de los Hechos de España, de R. Jiménez de Rada: introducción, traducción, notas e índices, Madrid, Alianza Editorial.

Ferrer Albelda, E. (1996), La España cartaginesa. Claves historiográficas para la historia de España, Sevilla, Universidad de Sevilla.

Kagan, R.L. (1995), «La corografía en la Castilla moderna. Género, historia, nación», Studia historica: Historia Moderna 13, 47-59. (Versión digital: «http://revistas.usal.es/index. php/Studia_Historica/article/view/4721/4737» [15/03/2018])

López Pardo, J.L. (2010), «Una isla errante entre las Afortunadas de Plinio», en Fornis, C., Gallego, J., López-Barja, P., Valdés, M. (eds.), Dialéctica histórica y compromiso social. Homenaje a Domingo Plácido, Zaragoza, Pórtico, 819-831.

Lucero Comas, L. (1994), Joan Margarit. Paralipomenon Hispaniae II. («http://www3.udg. edu/vell/ilcc/Eiximenis/html_eiximenis/portal_SH/textos/paralipomenon\%202.htm» [15/03/2018])

Menéndez Pidal, R. (1955² [1906]), Primera crónica general de España que mandó componer Alfonso el Sabio y se continuaba bajo Sancho IV en 1289. Madrid, Gredos.

Morales, A. (1574), La Crónica General de España, que continuaba Ambrosio de Morales, prosiguiendo delante de los cinco libros que el Maestro Florián de Ocampo dejó escritos. Alcalá de Henares. («https://books.google.ca/books?id=gTMmctT7Ts0C\&pg=PP1\#v=0nepage\&q\&f=false» $[23 / 11 / 2018])$

Morgado García, A. (2017² [2001]), Agustín de Horozco. Historia de Cádiz. Cádiz, Universidad de Cádiz.

Ocampo, F. (1553), Los cinco libros primeros de la Crónica General de España. Medina del Campo. («http://www.cervantesvirtual.com/obra/los-cinco-libros-primeros-de-la-cronica-general-de-espana/» [15/03/2018])

Ribichini, S. (1988), «El mito de Dido», en Moscati, S. (ed.), Los fenicios, Barcelona, Folio, 568-569.

Ribichini, S. (2000), «Sui miti della fondazione di Cadice», en Aubet, M..E., Barthelemy, M. (eds.), Actas del IV Congreso Internacional de Estudios Fenicios y Púnicos. Cádiz, Universidad de Cádiz, 661-668.

Seel, O. (1972² [1934]), Marcus Justinus Junianus. Epitoma Historiarum Philippicarum Pompeii Trogi. Stuttgart, Teubner.

Suárez de Salazar, J.B. (1985), Grandezas y antigüedades de la isla y ciudad de Cádiz. Cádiz, Caja de Ahorros de Cádiz. (Edición facsímil de la original de 1610).

Tate, R. B. (1970), Ensayos sobre la historiografía peninsular del siglo XV, Madrid, Gredos. Villa Prieto, J. (2010), "La ideología goticista en los prehumanistas castellanos: Alonso de Cartagena y Rodrigo Sánchez de Arévalo. Sus consideraciones sobre la unidad hispano-visigoda y el reino de León", Territorio, Sociedad y Poder 5, 125-145.

Villa Prieto, J. (2011), “Europa y los humanistas peninsulares de s. XV”, ¿Europa?, Oviedo, Universidad de Oviedo, 87-98.

Yardley, J.C. (1994), Justin, Epitome of the Philippic History of Pompeius Trogus. Atlanta, Scholars Press. 